\title{
Mechanical Characterization and Finite Element Investigation on Properties of PLA-Jute Composite
}

\author{
Kanak Kalita \\ Dept. of Mech. Engineering, \\ MPSTME, SVKM's NMIMS \\ Shirpur, Maharashtra, India
}

\author{
Rakesh Chaudhari \\ Dept. of Mech. Engineering, \\ MPSTME, SVKM's NMIMS \\ Shirpur, Maharashtra, India
}

\author{
M. Ramachandran \\ Dept. of Mech. Engineering, \\ MPSTME, SVKM's NMIMS \\ Shirpur, Maharashtra, India
}

\begin{abstract}
Composite materials are on high demand in recent days amongst high performance products that need to be strong enough in severe loading conditions. It can be developed with a suitable combination of matrix and reinforcement materials to meet the requirement of specific applications. The present work attempts to form composite plates using a combination of natural polymers and fibers to improve certain properties. The focus is to develop a biodegradable composite of comparable properties with those available commercially. The formed plates are tested to determine different mechanical properties such as tensile strength, impact resistance, hardness etc. The thermal parameters are also determined by DSC (Differential scanning calorimetry) test. A finite element analysis is conducted and the results have been compared with Graphite epoxy composite for checking the effective use of this material.
\end{abstract}

\section{Keywords}

Composite, Differential scanning calorimetry, Finite Element Analysis, Stress Concentration

\section{INTRODUCTION}

The Composite material is developed by the synthetic combination of multiple organic or inorganic materials to obtain specific properties. These combination improves the strength, stiffness to weight ratio, thermal behavior, fatigue life and corrosion and wear resistance.

The applications in which high strength and modulus is required, the properties of polymers is changed by blending the fibres. The use of fiber reinforced polymer matrix composites that gives high performance is well documented in previous research [1]. Epoxy resins are one of the thermosetting polymers that are popularly used for highperformance applications such as aero structures, improved bridge decks, racing cars etc. The literature survey suggest that epoxy resins possess excellent mechanical and thermal characteristics, improved chemical and corrosion resistance, and better deformation behavior under the highly loaded conditions [2]. According to Varga et. al. the mechanical properties of fiber-reinforced composites changes according to the type, quantity, fibre distribution and orientation of the constituent materials. Also the interfacial bonds and load transfer mechanism also play a vital role in its mechanical behavior [3]. Saha and Banerji [4] has observed an increase in flexural strength of unidirectional carbon Fibre/ Polymethyl methacrylate composite laminates having polyethylene Fibres plies at the bottom surface in the plate. The flexural strength of glass fiber composites and carbon fibers composites can be increased by using unidirectional steel wires tapes [5].

In recent years, a number of theories have been proposed to understand the composite structures. The static and dynamic responses along with vibration behavior of laminated composite plates have been extensively investigated. Pandya and Kant [6] has proposed a $\mathrm{C}_{0}$ continuous displacement finite element formulation of laminated composite plates under transverse loading using Higher order Shear Deformation theory. The static behavior of laminated composite and sandwich plates is studied analytically using Navier's technique based on higher order refined theory by Kant and Swaminathan [7]. Soltani et al. [8] has analyzed nonlinear tensile behavior of glass fibre reinforced aluminium laminates using finite element modeling. Attallah et al. [9] presented 3D solutions of laminated composite plates by using a combined finite strip and state space approach. Bharet al. [10] analyzed the significance of the HSDT over the FSDT for laminated composite stiffened plates by using FEM. Grover et al. [11] investigated the static and buckling analysis of laminated composite and sandwich plates in the framework of a new inverse hyperbolic shear deformation theory and this theory is based on shear strain shape function. Kumar et al. [12] studied static analysis of thick skew laminated composite plate with elliptical cutout based on 3-D elasticity theories. Riyah and Ahmed [13 investigated stresses of composite plates with different types of cutouts. Rezaeepazhand and Jafari [14] analytically analyzed the stresses of composite plates with a quasi-square cutout subjected to uniaxial tension based on Lekhnitskii's theory. Static analysis of isotropic rectangular plate with various support conditions and loads are studied by Vanamet al. [15] using finite element analysis (FEA). A recent study detailed the effect of cutout orientation on SCF [16].

\section{METHODOLOGY}

\subsection{Experimental methodology}

A mold cavity was prepared. The mold cavity was coated with a thin layer of aqueous solution of poly vinyl alcohol (PVA), which acted as a good releasing agent. Further, a thin coating of hard wax was applied and, finally, another thin layer of PVA was coated to the surface of the cavity. Each coat was allowed to dry for $20 \mathrm{~min}$ at room temperature. Firstly, fillers were dried in an oven at a temperature of $80{ }^{\circ} \mathrm{C}$ for $24 \mathrm{~h}$. The PLA being in crystal form was heated at $150{ }^{\circ} \mathrm{C}$ for $30 \mathrm{~min}$, until it comes to liquid state. 3 ply plate was made from the PLA and Jute combination and was placed in a vacuum oven, which was maintained at $100^{\circ} \mathrm{C}$ for three hours to complete the curing. After curing, samples were cut into ASTM standards. For impact strength, test specimen dimensions were cut as per ASTM D 256-88. The impact strength was determined using an IZOD impact tester (IS250U-FX). The test specimens were cut as per ASTM D 256-88 specifications. Five specimens were tested in each case and average values were recorded. The hardness of samples was measured using Rockwell hardness testing machine. In each case, five samples were tested and the average value 
tabulated. Test specimens were made according to the ASTM D 785. Instron Universal Testing machine (IUTM, seris-3369) was used for measuring tensile strength. The composite specimens were made as per the ASTMD638M to measure the tensile properties. Brinell and Rockwell hardness test were carried out. The testing was carried out at room temperature for all the samples. All the readings were taken $10 \mathrm{~s}$ after the indenter made firm contact with the specimen. All the sample surfaces were rubbed with smooth emery paper, which facilitates accurate reading.

\subsection{Finite Element Analysis methodology}

The problem of static analysis of plate was studied with the help of ANSYS v14.5. The basic workflow chart has been described in Fig. 1. An 8 node shell element has been used throughout the study. The element has eight nodes with six degrees of freedom at each node: translations in the $\mathrm{x}, \mathrm{y}$, and $\mathrm{z}$ axes, and rotations about the $\mathrm{x}, \mathrm{y}$ and $\mathrm{z}$ axes. Thus each element has 48 degrees of freedom in total. SHELL 281 is well suited for linear, large rotation, large strain non -linear applications. The basic diagram of the structure analyzed along with the constraints has been shown in Fig. 2. A 3 ply composite plate made of graphite epoxy has been modelled in ANSYS. The basic layup of the model has been shown in the Fig. 3. It is a good practice and efficient way to exploit symmetry in FEM analysis whenever possible. Hence in this case, only one quadrant of the plate has been modelled and meshed. Mapped meshing has used to get final mesh near the cut out periphery (Fig. 4). The final mesh near the cut-out periphery is needed to capture the SCF in this region. The values of Young's Modulus of Elasticity, volume of content, Modulus of Rigidity and Poisson's ratio obtained for jute fibre and PLA are as shown in Table 1.

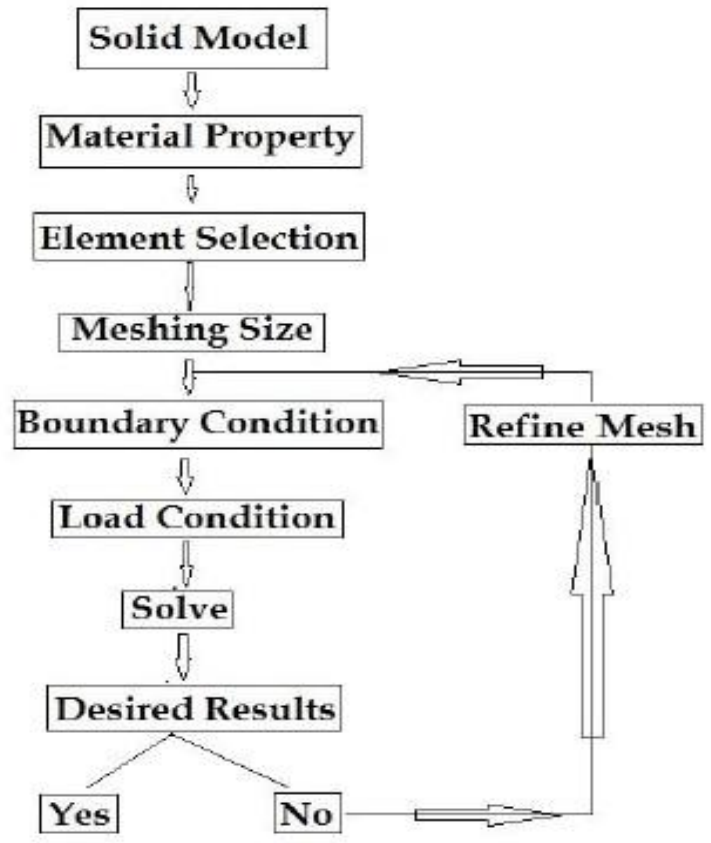

Fig 1: The basic workflow used in FEA

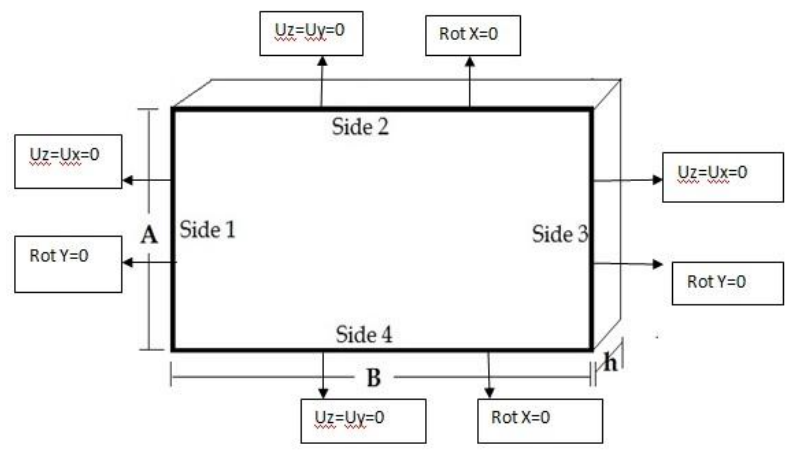

Fig 2: 3D model of the plate with constraints

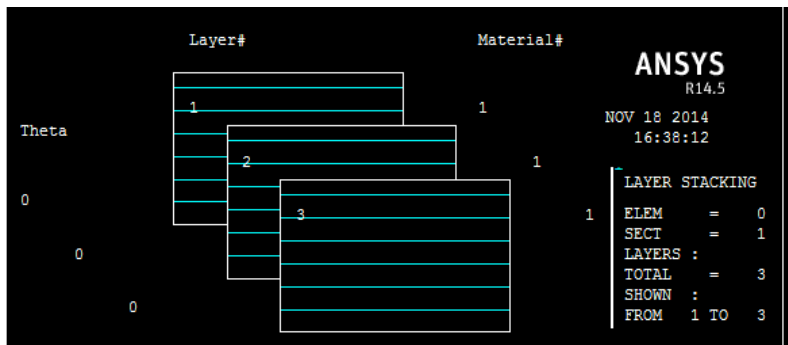

Fig. 3: Layup of graphite epoxy plate in ANSYS

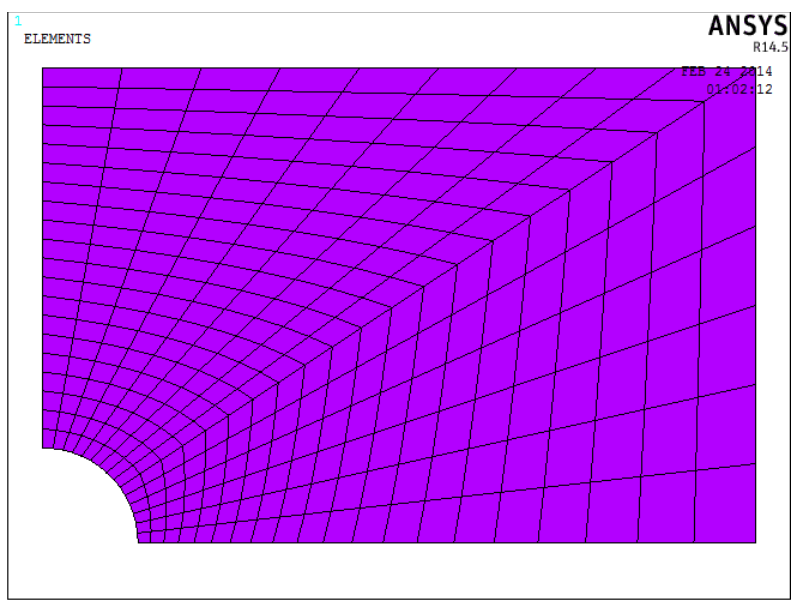

Fig. 4: Mapped meshing used in analysis

Table 1. Various physical properties of Jute and PLA

\begin{tabular}{|c|c|c|}
\hline Properties & JUTE & PLA \\
\hline $\mathrm{E}(\mathrm{GPa})$ & 20 & 10 \\
\hline $\mathrm{G}(\mathrm{GPa})$ & 7.24 & 3.7 \\
\hline \% Volume & 0.2 & 0.8 \\
\hline Poisson's ratio $\mathrm{V}$ & 0.38 & 0.35 \\
\hline
\end{tabular}

For Unidirectional analysis,

$$
E_{P J}=E_{J} V_{J}+E_{P} V_{P}
$$

Therefore, $E_{P J}=12$

$$
\frac{1}{G_{P J}}=\frac{V_{J}}{G_{J}}+\frac{V_{P}}{G_{P}}
$$

Therefore, $G_{P J}=4.1 \mathrm{GPa}$

$$
\mathrm{v}_{P J}=\mathrm{v}_{J} V_{J}+\mathrm{v}_{P} V_{P}
$$

Therefore, $v_{P J}=0.356$ 


\section{RESULTS AND DISCUSSION}

\subsection{Differential Scanning Calorimetry test}

DSC (Differential Scanning Calorimetry) has been performed to attain the glass transition temperature and the degradation temperature of the material. A powdered form of a very small part of the manufactured plate as required for DSC test has been analyzed. Fig. 5 shows the graph obtained from the test. The melting point of the material is around $156^{\circ} \mathrm{C}$ whereas the glass transition temperature or the degrading temperature of the material is $146.15^{\circ} \mathrm{C}$ which can be observed as the onset in the graph.

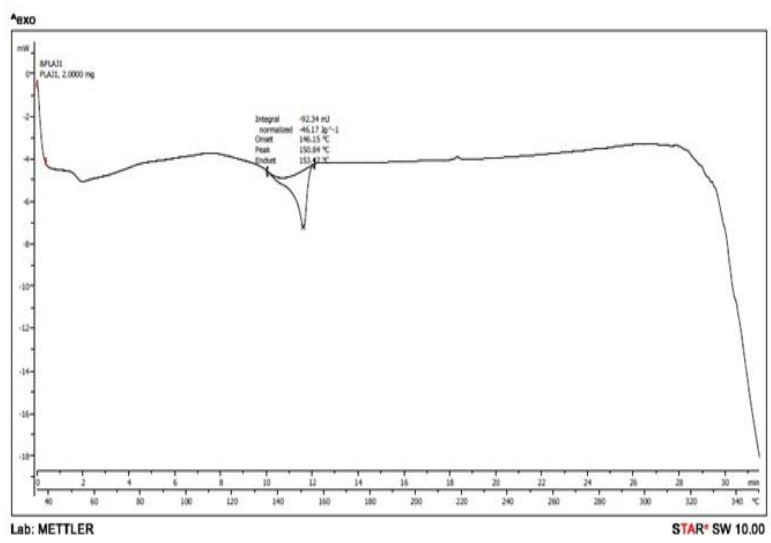

Fig. 5: Graph from DSC test

\subsection{Charpy Impact test}

The Impact test has been performed to obtain the performance of the material under impact loading conditions First the arm of the impact machine was given a free fall to obtain its standard or zero. Then the specimen was loaded in the machine and the arm is released. A difference of 3 divisions was obtained on the reading scale and 1 division is equal to 2 joules.

\subsection{Tensile test}

Tensile test has been done on a Universal Testing machine (UTM). The composite specimen was first made into a

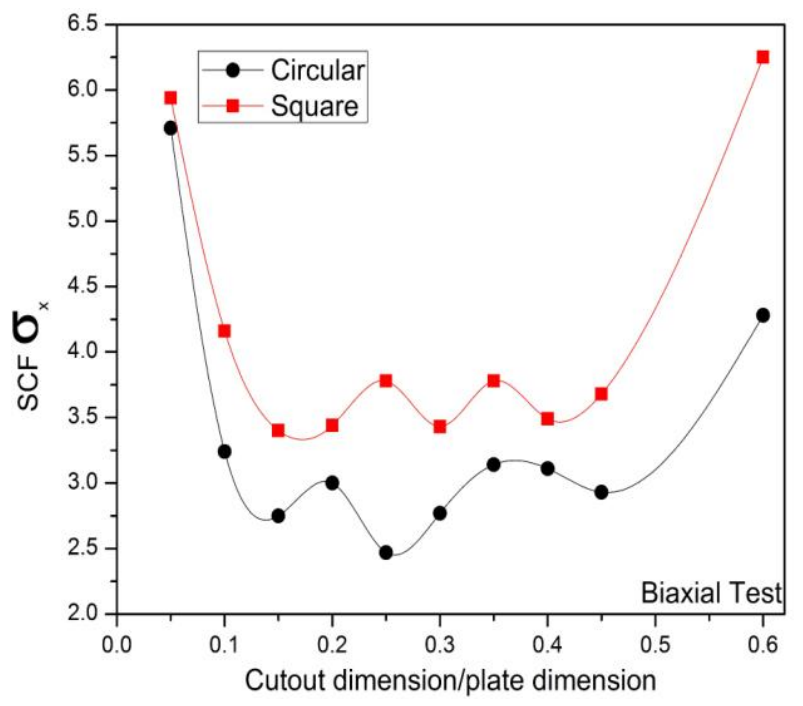

Fig. 6:SCF in X direction for Graphite Epoxv

dumble shape as required for the UTM. The claws of the UTM catch the upper and the lower part of this dumble shaped specimen and then it is pulled in the opposite direction. At one point, this specimen breaks into half due to the tensile force exerted by it. This point is known as the knee point or the break point. This point gives the maximum tensile force that can be exerted upon the material. Maximum Tensile force exerted by the composite (PLA and Jute fibre) $=42$ to $44 \mathrm{MPa}$.

\subsection{Rockwell Hardness Test}

The Load given $=100 \mathrm{kgf}$

Ball size (Indentor) $=1 / 4$ inches

The table on the machine states the dial on the machine which the user has to observe during the test. This depends upon the material that is being used. In this case, since a polymer has been used hence the red dial must be observed. Indenter size is also given on that table. The hardness of the material observed from the top side $=42$.

The hardness of the material observed from the rear side $=36$ Therefore, the range of RHN is from 36 to 42

Average Rockwell Hardness Number $=38$.

\subsection{Brinell hardness Test}

The process is similar to Rockwell Hardness test with a difference that was observed the indented diameter (d) done by the indentor using a Brinell testor microscope.

Load given $=187.5 \mathrm{kgf}$

Diameter of Indentor ball $=2.5 \mathrm{~mm}$

Diameter of Indent $=0.5 \mathrm{~mm}$

\subsection{FEM Results}

In classical mechanics, the SCF of plate with circular and

square hole for isotropic material is 3.0 but this value is not valid for an orthotropic material due to its directional properties. The maximum stress concentration factor is seen for Graphite Epoxy for both circular and square cross section is more than that in PLA-Jute. Thus in this case the manufactured PLA-Jute composite proves to be more efficient. Fig. 6 and Fig. 7 shows change in SCF in X direction for graphite epoxy and PLA-Jute composite respectively. Stress Concentration Factor across Y direction is

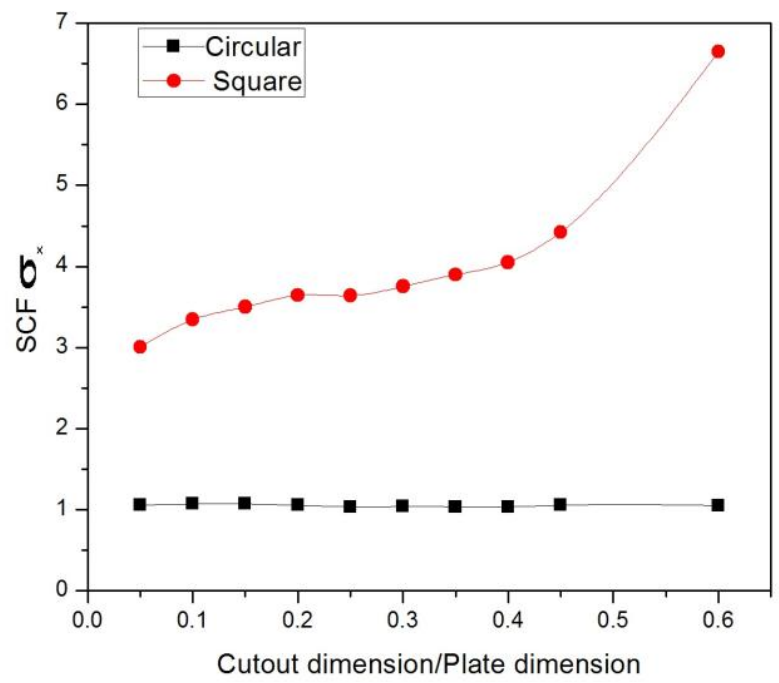

Fig. 7:SCF in X direction for PLA-.Jute

more in the commercial plate than in the manufactured PLAJute composite plate as seen from Fig. 8 and Fig. 9. Since if the stress concentration factor across a region is more than the 


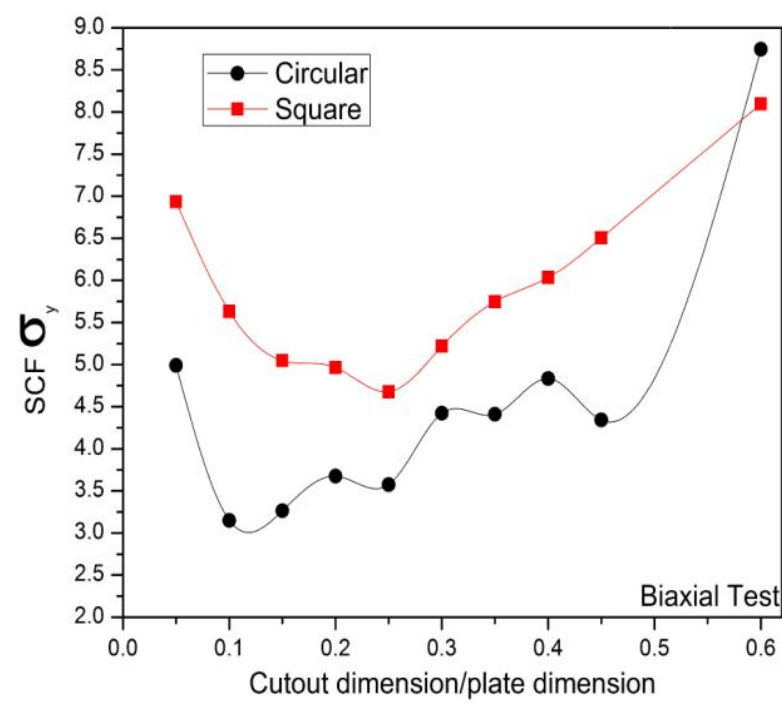

Fig. 8: SCF in Y direction for Graphite Epoxy

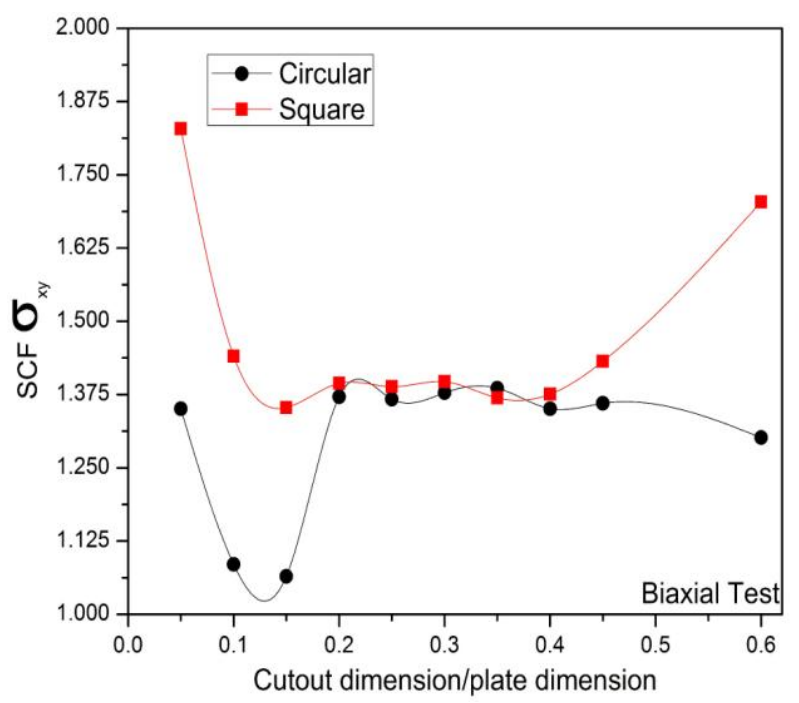

Fig. 10: SCF in XY direction for Graphite Epoxy

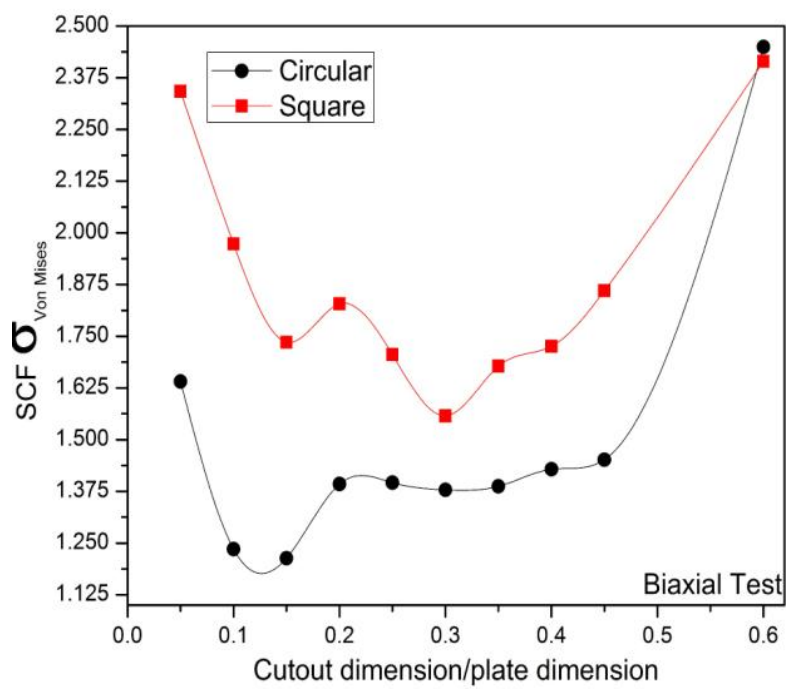

Fig. 12: Equivalent SCF for Graphite Epoxy

strength of the plate reduces considerably and thus the plate breaks. From Fig. 6 and Fig. 8 it is seen that SCF is more in $\mathrm{x}$

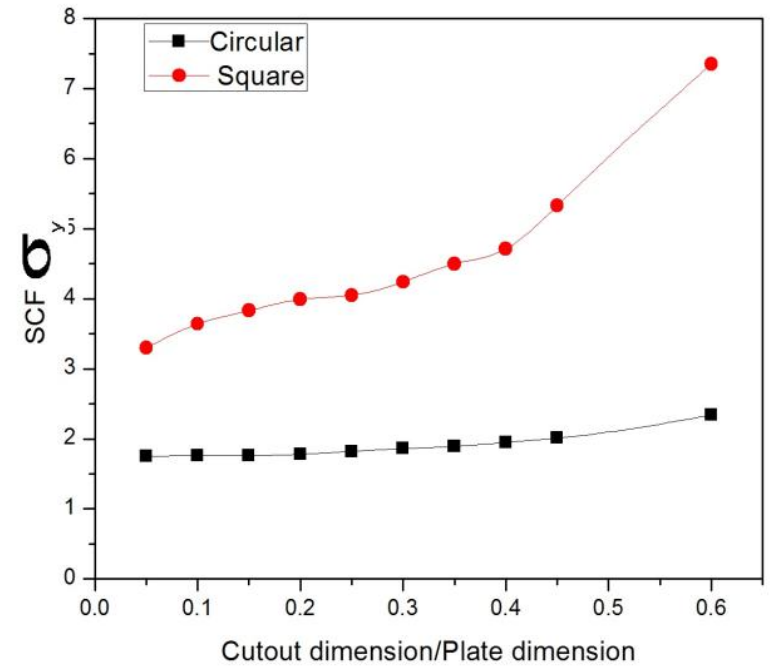

Fig. 9: SCF in Y direction for PLA-Jute

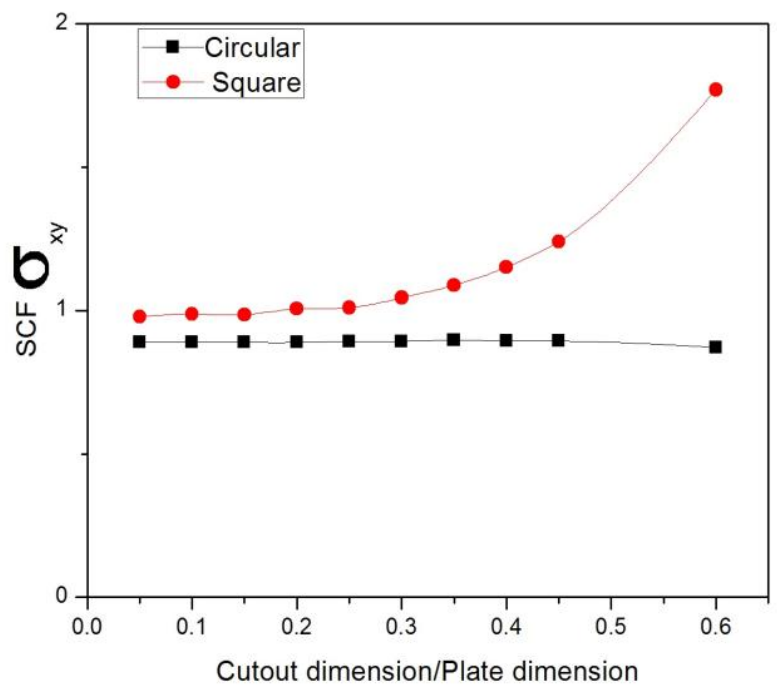

Fig. 11: SCF in XY direction for PLA-Jute

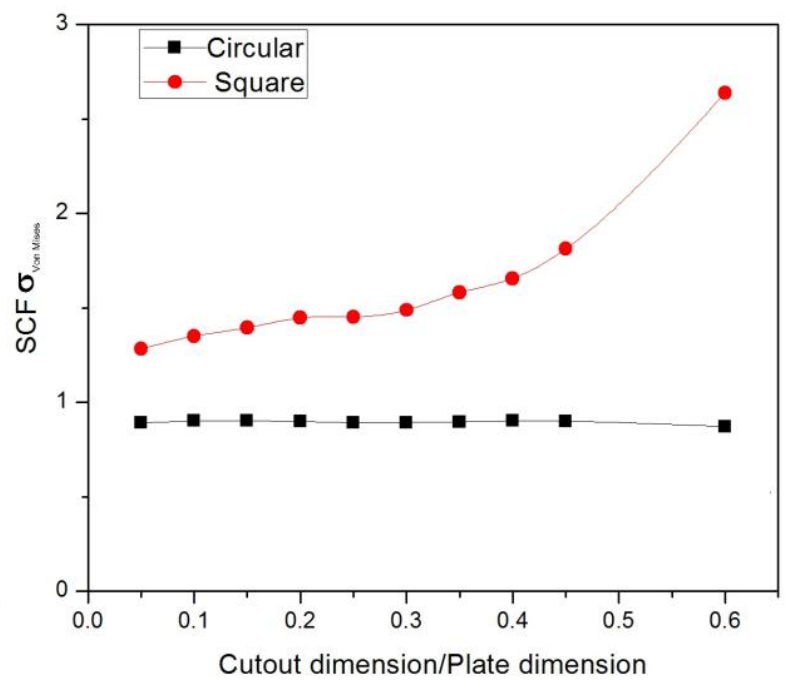

Fig. 13: Equivalent SCF for PLA-Jute

as well as in y direction across the Graphite Epoxy plate. Thus, the chances of strength reduction of that plate will 
increase as the load increase and therefore would prove to be less efficient than the manufactured PLA-Jute composite plate.

From Fig. 10 and Fig. 11 it is observe that in Graphite Epoxy SCF in $\mathrm{x}-\mathrm{y}$ plane for circular and square section has started from a high value, then decreases significantly but then again increases and then stays at a constant line for some dimensions. This signifies non uniformity and instability of the plate with mixed strength conditions.

However in the manufactured PLA-Jute composite plate, both SCFs are increasing at a uniform rate signifying stability and uniformity adding to the minimal effect on strength property of the plate.

In Fig. 12 and Fig. 13 Von Mises denotes that Stress Concentration Factor for Graphite Epoxy plate is larger than that of PLA-Jute which concludes that the manufactured PLAJute composite plate is more uniform and has achieved around $80 \%$ of the strength of an industrial produced commercial plate thus fulfilling the prime objective.

\section{CONCLUSION}

The various mechanical properties have been compared for Graphite Epoxy and composite. The values for Graphite

\section{REFERENCES}

[1] Shah, Shyamkumar, et al. "Effect of coal ash as a filler on mechanical properties of glass fiber reinforced material." International Journal of Applied Engineering Research, ISSN: 0973-4562.

[2] N. Hameed, P. A. Sreekumar, B. Francis, W. Yang and S. Thomas, "Morphology, Dynamic Mechanical and Thermal Studies on Poly(styrene-co-acrylonitrile) Modified Epoxy Resin/Glass Fibre Composites," Composites Part A, Vol. 38, No. 12, 2007, pp. 24222432.

[3] Cs. Varga, et al. "Improving the Mechanical Properties of Glass-Fibre-Rein- forced Polyester Composites by Modification of Fibre Surface," Materials and Design, Vol. 31, 2010, pp. 185- 193

[4] Saha, Nirmal, and Amar Nath Banerjee. "Stress relaxation behaviour of unidirectional polyethylene-glass fibres PMMA composite laminates." Polymer 37.20 (1996): 4633-4638.

[5] Matteson, Robert, and Roger Crane. Flexural Testing of Steel Wire Composite Beams Made with Hardwire (trademark) Unidirectional Tape. No. NSWCCD-65-TR 2003/48. NAVAL SURFACE WARFARE CENTER CARDEROCK DIV BETHESDA MD, 2003.

[6] Pandya B.N. and Kant T., Finite element analysis of laminated composite plates using a higher order displacement model, Composite Science and Technology, 32 (1988): pp. 137-155.

[7] Kant T. and Swaminathan K., Analytical solutions for the static analysis of laminated composite and sandwich plates based on a higher order refined theory, Composite Structures, 56 (2002): pp. 329-344.

[8] Soltani P., Keikhosravy M., Oskouei R. H. and Soutis C., Studying the tensile behaviour of GLARE laminates: A finite element modeling approach, Appl Compos Mater, 18 (2011): pp. 271-282.
Epoxy plate has been obtained from literature. The value of Glass Transition Temperature for PLA-Jute is $146.15^{\circ} \mathrm{C}$ while that of a commercial Graphite Epoxy is around $176.67^{\circ} \mathrm{C}$. The manufactured composite is able to withstand an impact of 6 Joules while that of Graphite Epoxy is around 5.9.The BHN for PLA-Jute composite plate is 15.686 while for the Graphite Epoxy it is around 57.64. The ultimate strength for PLA-Jute composite plate is $43 \mathrm{MPa}$ while that for Graphite Epoxy is around $48 \mathrm{MPa}$. The manufactured PLA-Jute composite has comparable properties with the commercially available graphite epoxy. The current PLA-Jute composite has been fabricated by hand layup technique while all the other composite plate are manufactured in industries by superior methods. The main drawback with the hand layup technique is inclusion of air pores which drastically reduce the mechanical properties of the composite. The manufactured PLA-Jute composite showed significant strength in the simulations. The SCF of PLA-Jute composite plate is generally less or comparable to the Graphite Epoxy plate. Also it is seen that the change in SCF with change in cutout dimension is uniform in case of PLA-Jute composite plate.

[9] Attallah, K. M. Z., J. Q. Ye, and H. Y. Sheng. "Threedimensional finite strip analysis of laminated panels." Computers \& Structures 85.23 (2007): 1769-1781.

[10] Bhar, A., S. S. Phoenix, and S. K. Satsangi. "Finite element analysis of laminated composite stiffened plates using FSDT and HSDT: A comparative perspective." Composite Structures 92.2 (2010).

[11] Grover, N, D. K. Maiti, and B. N. Singh. "A new inverse hyperbolic shear deformation theory for static and buckling analysis of laminated composite and sandwich plates." Composite Structures 95 (2013): 667-675.

[12] Kumar, N., M. S. R. Sarcar, and M. M. M. Murthy. "Static analysis of thick skew laminated composite plate with elliptical cutout." Indian Journal of Engineering \& Materials Sciences 16 (2009): 37-43.

[13] Riyah, N. K., and N. E. Ahmed. "Stress analysis of composite plates with different types of cutouts." Anbar Journal of Engineering Sciences 2 (2009): 11-29.

[14] Rezaeepazhand, J. A. L. I. L., and M. Jafari. "Stress concentration in metallic plates with special shaped cutout." International Journal of Mechanical Sciences 52.1 (2010): 96-102.

[15] Vanam, B. C. L., M. Rajyalakshmi, and R. Inala. "Static analysis of an isotropic rectangular plate using finite element analysis" Journal of Mechanical Engineering Research 4.4 (2012): 148-162.

[16] Kalita, K., and S. Halder. "Static Analysis of Transversely Loaded Isotropic and Orthotropic Plates with Central Cutout." Journal of the Institution of Engineers (India): Series C 95.4 (2014): 347-358. 